$\begin{array}{r}\text { PROGRESS IN } \\ \text { STEM CELL } \\ \hline \text { An Open Access Journal }\end{array}$

Available online at http://www.springer.com/globalsciencejournals

Research article

\title{
Good Manufacturing Practice-compliant Isolation and Culture of Human Bone Marrow Mesenchymal Stem Cells
}

\author{
Phuc Van Pham1,2, (iD , Nhan Lu-Chinh Phan'1, Dung Minh Le1, Phuong Thi-Bich Le³, Tung Dang-Xuan Tran³, Ngoc Kim Phan'1,2 \\ ${ }^{1}$ Laboratory of Stem Cell Research and Application, University of Science, Vietnam National University, Ho Chi Minh city, Vietnam \\ 2Faculty of Biology, University of Science, Vietnam National University, Ho Chi Minh city, Vietnam \\ ${ }^{3}$ Van Hanh Hospital, Ho Chi Minh city, Vietnam
}

\section{A R T I C L E I N F O}

\section{Article history:}

Received 15 August 2014

Accepted 15 September 2014

Published 14 December 2014

\section{A B S T R A C T}

Bone marrow mesenchymal stem cells (BM-MSCs) are multipotent stem cells that can differentiate into different kinds of mesenchymal cells such as osteoblasts, chondroblasts, and adipocytes. These cells were identified a long time ago and are considered the first discovered source of MSCs. BM-MSC transplantation is used to treat bone disease, myocardial infarction, stroke, and diabetes mellitus. This study aimed to provide a new method for the in vitro primary culture and secondary culture of BM-MSCs that is compliant with good manufacturing practices, for use in clinical applications. Bone marrow was aspirated from the hipbone by using special needles and syringes. Mononuclear cells (MNCs) were isolated from the marrow by using Ficoll-Hypaque gradient centrifugation. These MNCs were cultured in DMEM/F12 medium supplemented with $2.5 \%, 5 \%$, and $10 \%$ activated platelet rich plasma (aPRP) in the experimental groups and $10 \%$ FBS in the control group to obtain BM-MSCs. The results showed that APRP could be replaced with FBS for isolation and proliferation of BM-MSCs. BM-MSCs cultured in both DMEM/F12 medium supplemented with aPRP and DMEM/F12 medium supplemented with FBS exhibited the characteristic phenotype of MSCs, such as being positive for CD44, CD73, CD90, and CD105, and being negative for CD14, CD34, CD45, and HLA-DR. They also successfully differentiated into adipocytes and osteoblasts. More importantly, BM-MSCs strongly proliferated in medium supplemented with aPRP, maintained the normal karyotype, and non-tumorigenesis in the athymic mice. Thus, this study provides an advanced protocol that is beneficial for the clinical applications of BM-MSCs.

Keywords: Bone marrow, Mesenchymal stem cell, GMP, Serum free medium, Platelet rich plasma.

* Corresponding author: Tel: +84 90 3870153,Email: pvphuc@hcmuns.edu.vn

(c) The Author(s) 2014. This article is published with open access by BioMedPress (BMP), Laboratory of Stem Cell Research and Application, Vietnam National University, Ho Chi Minh city, Vietnam This article is distributed under the terms of the Creative Commons Attribution License (CC-BY 4.0) which permits any use, distribution, and reproduction in any medium, provided the original author(s) and the source are credited. 


\section{Introduction}

Bone marrow-derived mesenchymal stem cells (BM-MSCs) have long been used in both preclinical and clinical studies. BM-MSCs were first discovered by Friedenstein in 1968 (Friedenstein et al., 1968). Based on the first demonstration by Friedenstein, these cells were also seen in other tissues such as umbilical cord blood (Pham et al., 2014), umbilical cord (Leite et al., 2014), adipose tissue (Van Pham et al., 2013), dental pulp (Ferro et al., 2014), placenta (Brooke et al., 2009), and menstrual blood (de Carvalho Rodrigues et al., 2012). To confirm which stem cells are MSCs, Dominici et al. (2006) suggested three criteria: plastic adherence when maintained in standard culture conditions, expression of CD105, CD73, and CD90 and non-expression of CD45, CD34, CD14, or CD11b, CD79 alpha, or CD19 and HLA$D R$, and successful differentiation into osteoblasts, adipocytes, and chondroblasts in vitro (Dominici et al., 2006).

BM-MSCs are used to pre-clinically treat diseases in animal models of Alzheimer's and Parkinson's diseases (Danielyan et al., 2014; Danielyan et al., 2011), rheumatoid arthritis (Papadopoulou et al., 2012), amyotrophic lateral sclerosis (Chan-Il et al., 2013), diabetes (Ezquer et al., 2009), etc. They are used clinically in humans to treat idiopathic pulmonary fibrosis (Chambers et al., 2014), cirrhosis (hepatocellular carcinoma) (Vainshtein et al., 2014), cirrhotic rats (Li et al., 2013), autoimmune diseases (Lee et al., 2014), cartilage disease (Veronesi et al., 2013), etc.

To increase the number of BM-MSCs, BM-MSCs are subjected to long-term culture in vitro. However, in most studies, MSCs were cultured in media containing xenogeneic additives such as fetal bovine serum (FBS) (Choudhery et al., 2013; Huang et al., 2014; Odabas et al., 2014). These media are associated with risks such as prion-mediated infections, viral transmission, and adverse immunological reactions. However, serum-free media are commercially available for use in BM-MSC culture. The main limitations of these media are their high cost and complexity. In fact, when grown in serum-free media, BMMSCs hardly adhere to culture-flask surfaces; hence, all culture flasks must be pre-coated with adherent matrixes.

In this study, we established an animal productfree expansion protocol by using autologous activated platelet rich plasma. During the procedure, all components of animal origin, such as trypsin, were not used. Thus, because this protocol is free of animal products, it is safe and feasible for large-scale BM-MSC isolation and expansion for use in clinical applications.

\section{Materials-Methods}

\section{Bone Marrow and Peripheral Blood Collection}

The project was approved by the local ethics committee. Five donors participated in this study. In total, $20 \mathrm{~mL}$ of bone marrow was aspirated from each donor after obtaining informed consent. The collection was performed in accordance with the standards of the local ethics committee. Besides BM samples, $20 \mathrm{~mL}$ peripheral blood was also collected from each donor. Both BM and peripheral blood were anticoagulated by using CDPA solution. All samples were immediately transferred to the laboratory.

\section{MNC Isolation and Activated PRP Preparation}

Mononuclear cells (NMCs) were isolated from the bone marrow. The BM samples were diluted at a ratio of 1:1 with phosphate-buffered solution (PBS) and then subjected to density centrifugation using Ficoll-Hypaque (1.077 g/mL; Sigma-Aldrich, St Louis, MO, USA). BM samples were centrifuged at $3000 \mathrm{rpm}$ for $30 \mathrm{~min}$. MNCs were collected from the interphase of the centrifuge tube. The collected MNCs were washed twice with PBS and then used for further experiments.

Peripheral blood samples were used to produce activated PRP (aPRP). ACD anti-coagulated peripheral blood samples were centrifuged in two steps to get PRP. In the first step, these samples were centrifuged at $500 \times g$ 
for 5 min to obtain plasma. In the second step, the plasma samples were centrifuged at $800 \times g$ for $10 \mathrm{~min}$ to obtain platelet pellets at the bottom of the tubes. To prepare aPRP, a third of the plasma volume and the platelet pellet was collected and re-suspended, following which $100 \mu \mathrm{L}$ $\mathrm{CaCl}_{2}$ per $1 \mathrm{~mL}$ of PRP was added to activate growth factor release. The samples were then incubated at $37^{\circ} \mathrm{C}$ for $30 \mathrm{~min}$ or until clotting occurred.

\section{Primary Culture}

Primary culture was performed as described in a previously published study (Pham et al., 2014). Five BM samples were used for primary culture. MNCs were cultured in DMEM/F12 medium containing 1\% antibioticantimycotic (Sigma-Aldrich) and various concentrations of autologous aPRP $(2 \%, 5 \%, 7 \%$, or $10 \%)$ or $10 \%$ fetal bovine serum (FBS) for the control. The cells were plated at a density of $5 \times 10^{4} \mathrm{cells} / \mathrm{mL}$ in T-75 flasks (Corning) and incubated at $37^{\circ} \mathrm{C}$ with $5 \% \mathrm{CO}_{2}$. After three days of culture, $6 \mathrm{~mL}$ of fresh medium was added to each T-75 flask. The medium was replaced with fresh medium every 4 days until the cells reached $70-80 \%$ confluence. The efficiency of the media was evaluated by considering the time required for adherent cells to appear and reach 70$80 \%$ confluence for the first subculture.

\section{Secondary Culture}

After successful primary culture, the samples were sub-cultured to evaluate the effects of various media. The proliferation rate was evaluated by the XCELLIgence system (Roche Applied Science, Indianapolis, IN, USA). A total of $1 \times 10^{3}$ cells were seeded into each well of a 96-well E-plate in triplicate. The culture plates were placed into the XCELLIgence system and incubated at $37^{\circ} \mathrm{C}$ in the presence of $5 \% \mathrm{CO}_{2}$. Cell proliferation was monitored for $300 \mathrm{~h}$, with the medium being replaced every third day. Both the cell doubling time and slope value were determined by a software of the XCELLIgence system.

\section{Flow Cytometry}

Cell markers were analyzed by following a previously published protocol. Briefly, cells were washed twice in PBS containing $1 \%$ bovine serum albumin (Sigma-Aldrich). The cells were then stained with antiCD13-FITC, anti-CD14-FITC, anti-CD34-FITC, antiCD44-PE, anti-CD45-FITC, anti-CD73-FITC, anti-CD90PE, anti-CD105-FITC, anti-CD106-PE, anti-CD166-PE, or anti-HLA-DR-FITC antibodies (all purchased from BD Biosciences, San Jose, CA, USA). Stained cells were analyzed by FACSCalibur flow cytometer (BD Biosciences). Isotype controls were used in all analyses.

\section{In Vitro Differentiation}

For differentiation into adipogenic cells, BMMSCs were differentiated as described previously. Briefly, passage five cells were plated at a density of $1 \times 10^{4}$ cells/well in $24-w e l l$ plates. At $70 \%$ confluence, the cells were cultured for 21 days in DMEM/F12 containing $0.5 \mathrm{mmol} / \mathrm{L}$ 3-isobutyl-1-methyl-xanthine, $1 \mathrm{nmol} / \mathrm{L}$ dexamethasone, $0.1 \mathrm{mmol} / \mathrm{L}$ indomethacin, and $10 \%$ FBS (all purchased from Sigma-Aldrich). Adipogenic differentiation was evaluated by observing lipid droplets in cells, stained with Oil Red, under a microscope.

For differentiation into osteogenic cells, BMMSCs were plated at a density of $1 \times 10^{4}$ cells/well in 24well plates. At $70 \%$ confluence, the cells were cultured for 21 days in DMEM/F12F12 containing 10\% FBS, 10$7 \mathrm{~mol} / \mathrm{L}$ dexamethasone, $50 \mu \mathrm{mol} / \mathrm{L}$ ascorbic acid-2 phosphate, and $10 \mathrm{mmol} / \mathrm{L} \beta$-glycerol phosphate (all purchased from Sigma-Aldrich). Osteogenic differentiation was confirmed by Alizarin red staining.

\section{Tumorigenicity Assay}

The tumorigenicity of BM-MSCs was examined in athymic nude mice. All manipulations of mice were approved by the Local Ethics Committee of Stem Cell Research and Application, University of Science (Ho Chi Minh City, Vietnam). Each mouse was injected subcutaneously with $5 \times 10^{6}$ cells (three mice per group). As a positive control, the mice were also injected with breast cancer cells at a different site. Tumor formation in mice was followed up for three months. 


\section{Statistical Analysis}

The significance of differences between mean values was assessed by $t$-tests and analysis of variance. A P-value of less than 0.05 was considered to be significant. All data were analyzed by Prism 6 software.

\section{Results}

\section{Bone Marrow Isolation and Primary Culture}

By daily observation under an inverted microscope, the adherent cells were found to appear sooner in groups $10 \%$ FBS and $10 \%$ PRP on day 2 than in groups $2.5 \%$ PRP and $5 \%$ PRP on day 3 . Therefore, the figures captured on day 3 show that a few adherent cells appeared on the flask surfaces. Fig. 1 shows that there were fewer cells appearing in the same microscopic field in groups treated with a lower concentration of PRP. After 10 days, cells reached approximately $70 \%$ confluence in almost samples of four groups. These cells were continuously sub-cultured for four passages. The cells in this passage were used for further experiments such as evaluation of surface marker expression, cell proliferation, cell differentiation, karyotyping, and tumorigenicity.

\section{Expression of Surface Markers in Cells of the Four Groups}

The results are presented in Fig. 2. These results showed that MSCs cultured in four different media expressed similar surface markers of MSCs. The MSCs of these four groups were strongly positive for CD44, CD73, and CD90; $95.5 \%, 98.71 \%$, and $99.12 \%$, respectively, for group 10\% FBS; 96.21\%, 97.19\%, and 98.31\%, respectively, for group 2.5\% PRP; $97.31 \%, 96.78 \%$, and $97.18 \%$, respectively, for group 5\% PRP; and $97.31 \%$, 95.81\%, and $96.17 \%$ respectively, for group 10\% PRP. The differences between the percentages of positive markers were non-significant. Moreover, the MSCs in these four groups were also similar with respect to the non-expression of markers such as CD14, CD34, and CD45. In fact, there were only $2.13 \%, 1.18 \%, 2.11 \%$, $1.11 \% \mathrm{CD}^{+} 4^{+}$cells, $0.11 \%, 0.45 \%, 0.31 \%, 0.19 \% \mathrm{CD}^{+} 4^{+}$ cells, and $0.33 \%, 0.31 \%, 0.71 \%, 0.49 \% \mathrm{CD}^{2} 5^{+}$cells, respectively, for groups $10 \%$ FBS, $2.5 \%$ PRP, $5 \%$ PRP, and $10 \%$ PRP
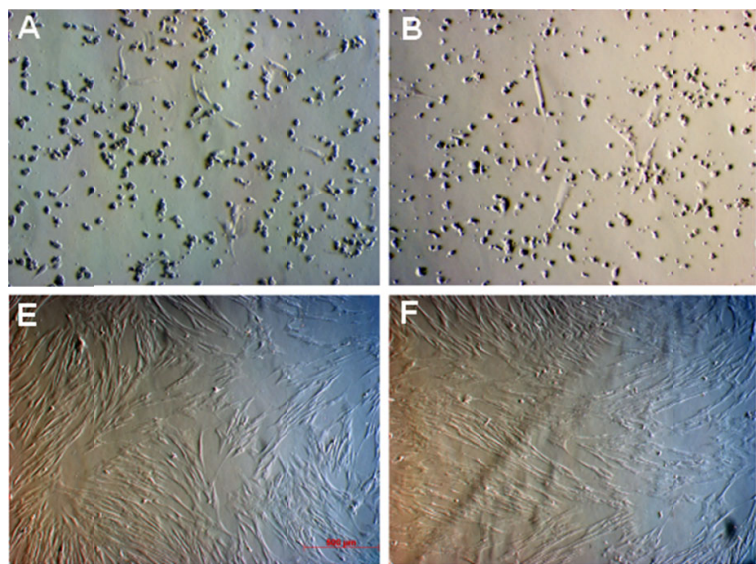
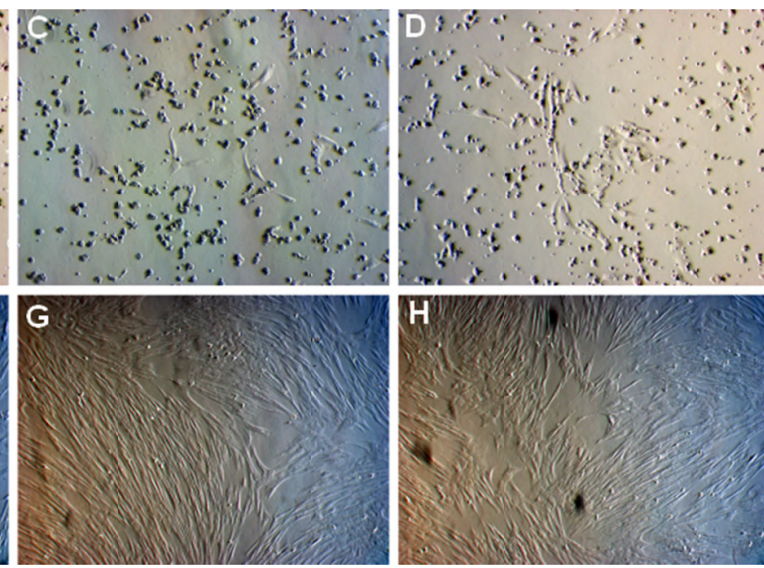

Figure 1. Primary culture of MNCs in four kinds of medium. A-D: images of the samples were captured under an inverted microscope at day 3 for group 10\% FBS (A), 2.5\% PRP (B), 5\% PRP (C), and 10\% PRP (D). E-H: images of the samples were captured under an inverted microscope at day 10 for group 10\% FBS (E), 2.5\% PRP (F), 5\% PRP (G), and 10\% PRP (H). Magnification 100X. 


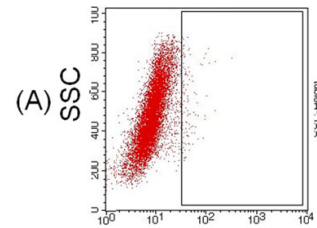
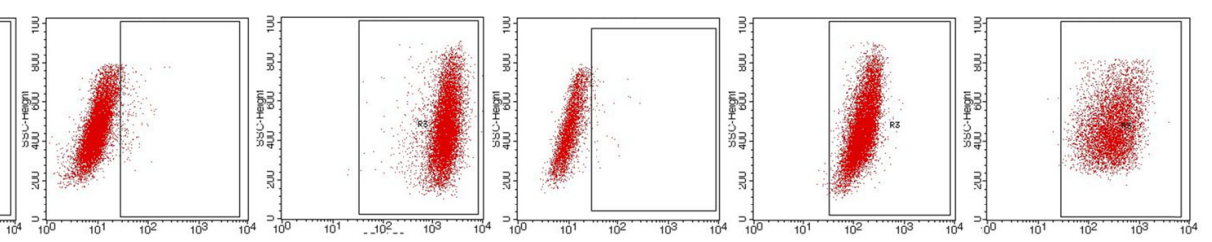

(B)
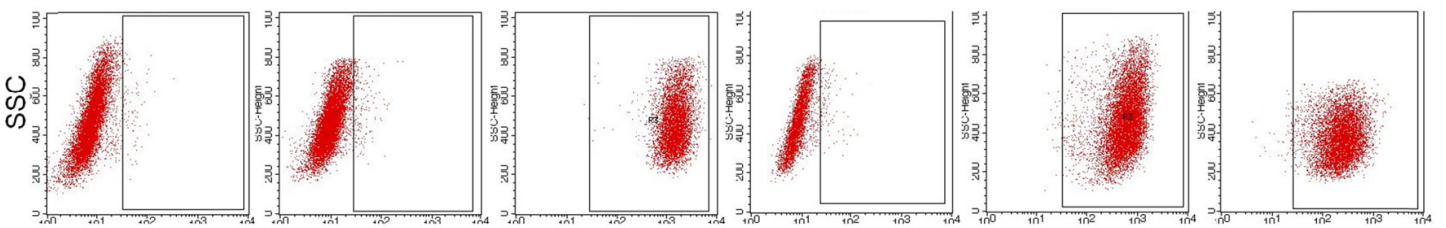

(C)
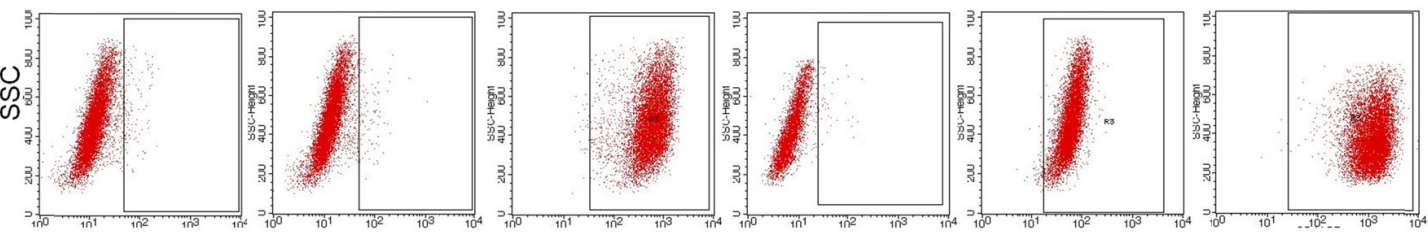

(D)
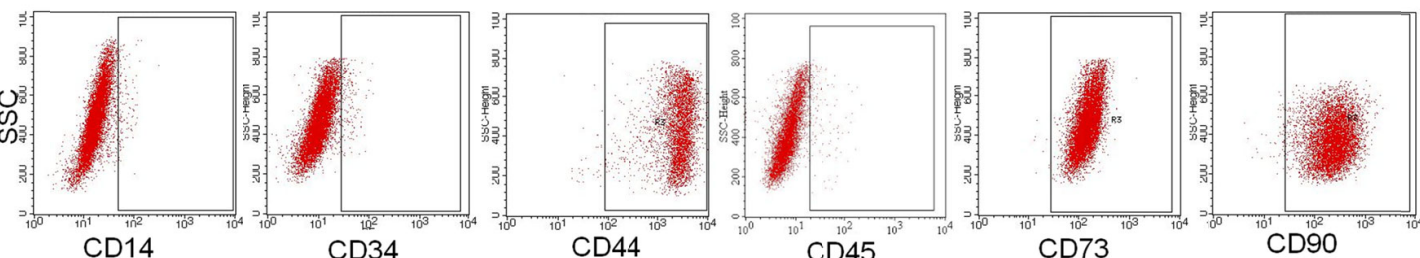

Figure 2. Expression of mesenchymal stem cell markers in cells of the four different groups. Cells in the four groups expressed CD44, CD73, CD90, and CD105 and were negative for CD14, CD34, CD45, and HLA-DR. Line A: group 10\% FBS, line B: group 2.5\% PRP; line C: group 5\% PRP, and line D: group 10\% PRP.

\section{Differentiation Potential of BM-MSCs in the Four Different} Groups

BM-MSCs in the four groups successfully differentiated into both adipocytes and osteoblasts. After induction with adipogenesis-inducing medium, BM-MSCs in the four groups accumulated lipid droplets in the cellular cytosol from day 14; this could be visualized under an inverted microscope (Fig. 3). The lipid droplets gradually increased in size, and at day 21, these droplets could clearly be visualized and stained red with Oil Red (Fig. 3). Similarly, the shape of these cells also changed when incubated in osteogenesis-inducing medium. After 14 days of induction, BM-MSCs exhibited the characteristic longer shape associated with fibroblasts (Fig. 3). More importantly, these induced cells stained positive with Alizarin Red.

Proliferation of BM-MSCs in the Four different Media 

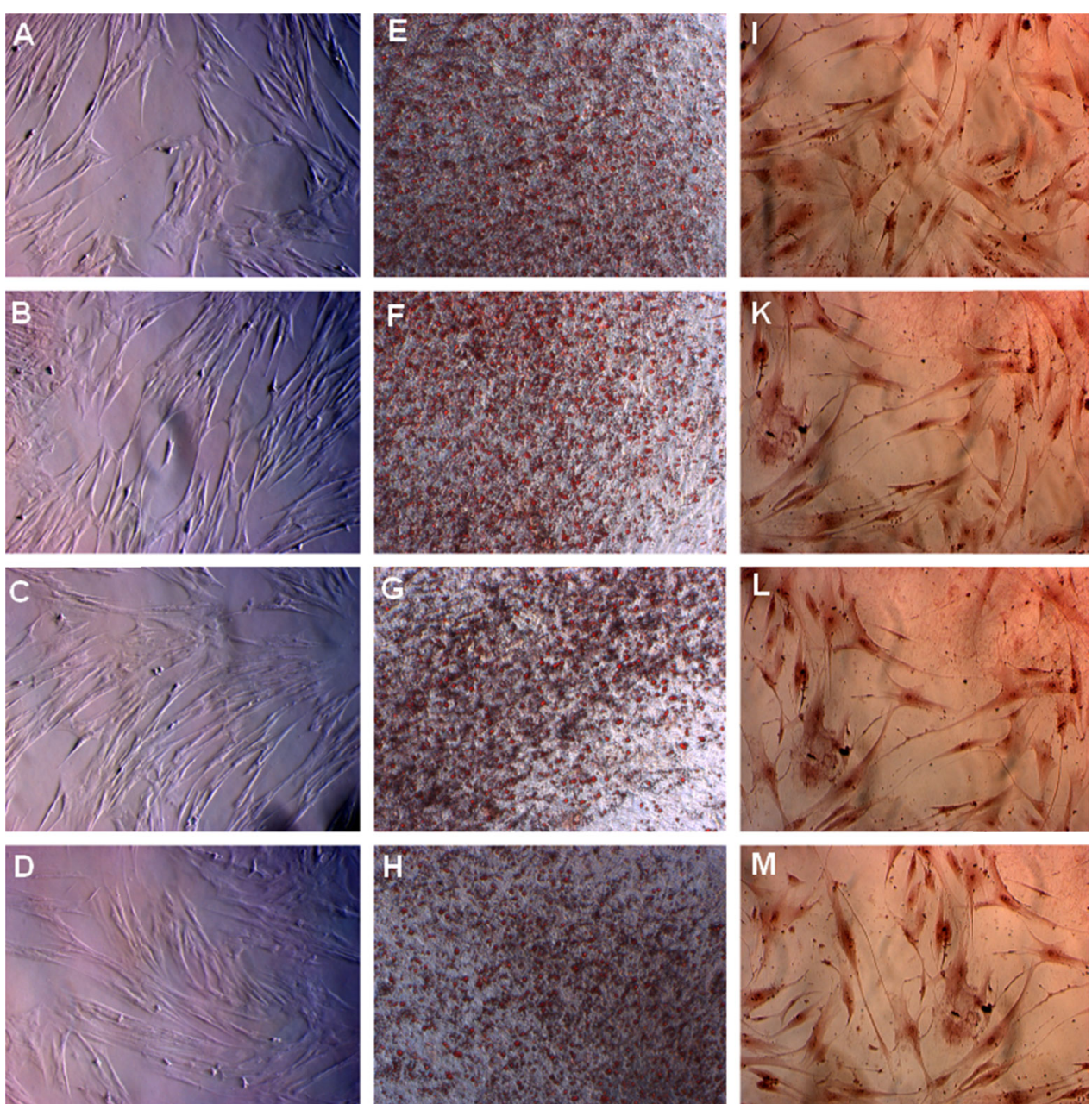

Figure 3. MSCs in the four groups successfully differentiated into adipocytes and osteoblasts in vitro. MSCs accumulated lipids in the cell vacuole and formed lipid droplets that were stained with Oil Red (E, F, G, and H depict groups 10\% FBS, $2.5 \%$ PRP, 5\% PRP, and 10\% PRP, respectively). MSCs also stored $\mathrm{Ca}^{2+}$ as an osteoblast property that stained positive with Alizarin Red (I, K, L, and M depict groups 10\% FBS, 2.5\% PRP, 5\% PRP, and 10\% PRP, respectively). Magnification 100X.

Proliferation rates of BM-MSCs were different among the four media. Based on the proliferation curve depicted in Fig. 4A, the results showed that BM-MSC proliferation in the $10 \%$ FBS group was significantly slower than that in 5\% PRP and 10\% PRP groups. However, it was equivalent to that observed in $2.5 \%$ PRP group. These observations were confirmed by doubling time and slope value analysis (Fig. 4). As presented in Fig. 4, from $0 \mathrm{~h}$ to $87 \mathrm{~h}$, the doubling time and slope values were similar in four groups; however, from $87 \mathrm{~h}$ to $290 \mathrm{~h}$, the doubling time of BM-MSCs in groups 5\% PRP and $10 \%$ PRP was significantly reduced compared to the doubling time in groups $2.5 \% \mathrm{PRP}$ and $10 \%$ FBS. Doubling time of BM-MSCs in $10 \%$ FBS and $2.5 \%$ PRP groups was similar. In contrast to the doubling time values, slope values gradually increased from group $10 \%$ FBS, 2.5\% PRP, 5\% PRP, and 10\% PRP. These results were clearly different from those of the control (blank wells). 


\section{BM-MSCs Maintained Normal Karyotypes}

BM-MSCs of the four groups at $10^{\text {th }}$ passage were used for karyotype analysis. The results showed that at the $10^{\text {th }}$ passage, the BM-MSCs in all the four groups (10\% FBS, 2.5\% PRP, 5\% PRP, and 10\% PRP) maintained the normal karyotype $(2 n=46$ chromosomes $)$.

\section{Tumorigenesis of BM-MSCs in Athymic Mice}

BM-MSCs cultured in the various media were injected into athymic nude mice. As a positive control, breast cancer cells were injected at a different location. The results showed that BM-MSCs could not form tumors in athymic nude mice, while breast cancer cells formed tumors in the control group after one month.

\section{Discussion}

BM-MSCs are the most popular source of mesenchymal stem cells used in clinical applications. To date, both autologous and allogenic BM-MSCs are used for the treatment of diseases. For example, Prochymal ${ }^{\mathrm{TM}}$,
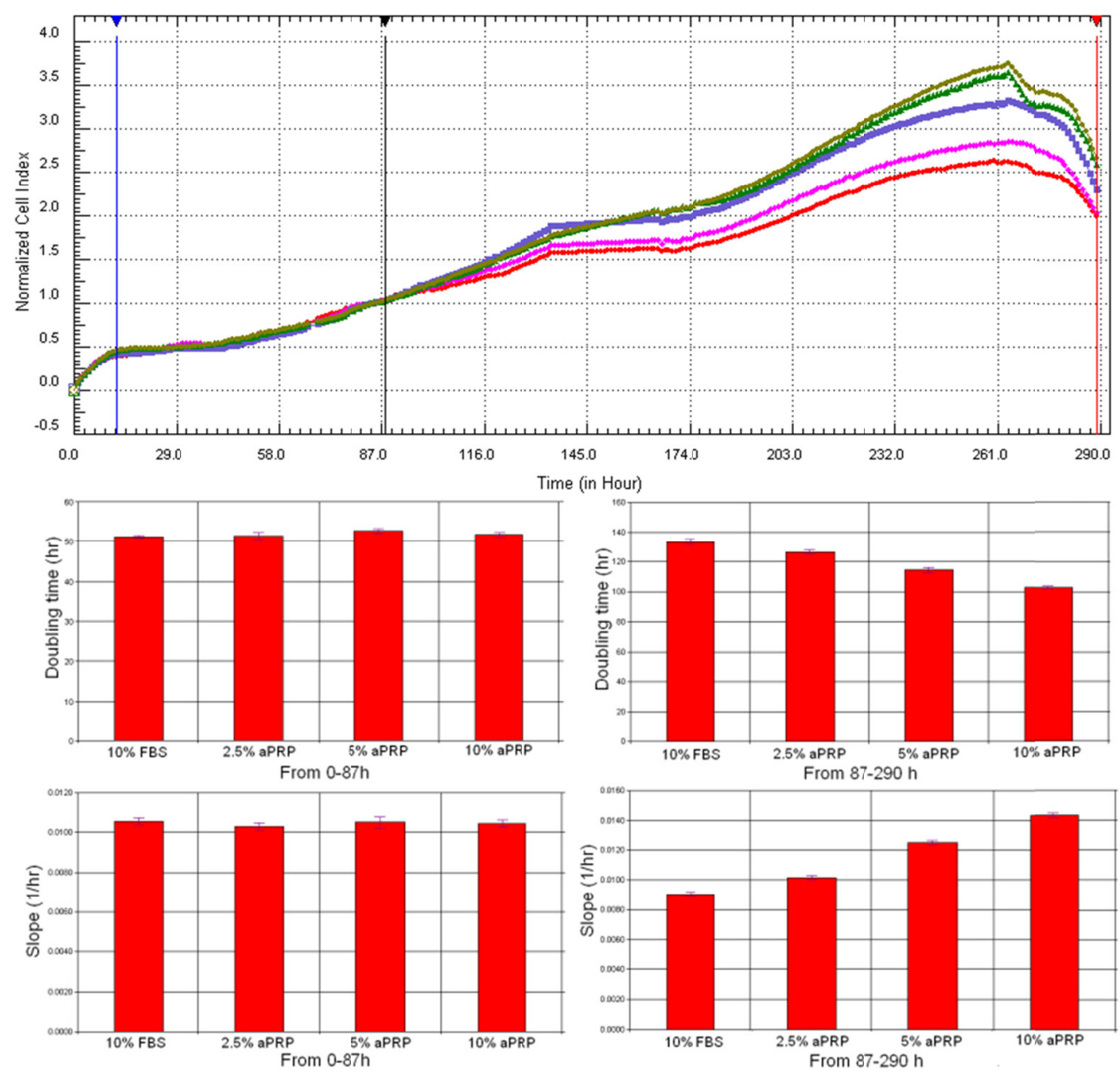

Figure 4. Proliferation of BM-MSCs in the four different media. BM-MSC proliferation in group 10\% FBS was similar to that in group 2.5\% PRP, but slower than that observed in groups 5\% PRP and 10\% PRP (A). Red line: 10\% FBS, Pink line: $2.5 \%$ aPRP, Violet line: $7.5 \%$ aPRP; Green and grey lines: $10 \%$ aPRP. 
a product obtained from BM-MSCs, is approved as a stem cell drug for the treatment of graft versus host disease (GVHD) (Kebriaei et al., 2009; Vaes et al., 2012). In the clinicaltrial.gov database, there were more than 200 registered trials with about 10 kinds of diseases that have been treated by BM-MSC transplantation. Therefore, expansion of BM-MSCs for both autologous and allogenic transplantation is essential for the application of stem cells in the treatment of diseases.

In this study, we successfully cultured BM-MSCs in xenogeneic protein-free conditions. In most previously published studies, BM-MSCs were cultured in media supplemented with FBS or FCS. FBS and FCS contained several xenogeneic proteins as well as infectious agents, including viruses and prions. Therefore, BM-MSCs could be contaminated with these components of bovine serum. After transplantation, these components could elicit an immune response in the recipient or transmit viruses or prions to cause critical diseases in human, which is riskier. By replacement of FBS or FCS with PRP, BM-MSCs can be cultured in conditions that are entirely free of bovine serum.

However, the next question to be addressed was whether cultivation of BM-MSCs in PRP-supplemented medium could cause changes in the BM-MSCs. In the next experiment, we evaluated the phenotype, differentiation potential, as well as karyotype of BMMSCs. BM-MSCs were cultured in PRP-supplemented medium well-done conserved MSC properties. Similar to BM-MSCs cultured in FBS medium, MSCs in PRP medium satisfied with minimum criteria of MSCs that Dominici et al. suggested in 2006 (Dominici et al., 2006). In fact, these cells were positive for CD44, CD73, CD90 and CD105 and negative for CD14, CD34, CD45, and HLA-DR. This phenotype also agreed with that reported in previously published studies (ludicone et al., 2014; Narbona-Carceles et al., 2014; Robey et al., 2014).

Although culture medium with $10 \%$ FBS excellently enhanced cell adherence to the flask surface in a manner similar to that observed in culture medium with
$10 \%$ PRP during the primary culture, during the secondary culture, PRP efficiently stimulated BM-MSC growth. In fact, at $2.5 \%$ PRP concentration in the culture medium, proliferation rates of BM-MSCs in both 2.5\% PRP medium and $10 \%$ FBS medium were similar. Moreover, their proliferation rates were significantly different between 10\% FBS medium and 5\% PRP and 10\% PRP media These results showed that PRP is a rich source of natural human growth factors. Moreover, these growth factors triggered BM-MSC growth. PRP also strongly stimulated the proliferation of MSCs that originated from other tissues such as umbilical cord blood (Murphy et al., 2012; Pham et al., 2014), adipose tissue (Atashi et al., 2014; Van Pham et al., 2014), and human dental stem cells (Lee et al., 2011). The last criterion evaluated was the differentiation potential of BM-MSCs into mesenchymal cells such as adipocytes, osteoblasts, and chondrocytes. The BM-MSCs cultivated in PRP medium and FBS medium could differentiate into adipocytes and osteoblasts. BM-MSCs cultured in PRP-supplemented medium were also found to maintain the MSC phenotype.

To satisfy the stem cells for transplantation, BMMSCs cultured in PRP medium were examined for changes in the normal karyotype and for their tumorigenicity. The results demonstrated that PRP did not affect the karyotype of BM-MSCs. At the $10^{\text {th }}$ passage, BM-MSCs in both PRP- or FBS-supplemented media maintained the normal karyotypes $(2 n=46)$. Owing to the normal karyotype, these cells also could not form tumors in the athymic mice. Considering these analysis results, PRP could replace FBS in BM-MSC culture and satisfy the criteria of MSCs used for clinical transplantation.

\section{Conclusion}

BM-MSCs are important autologous stem cells for regenerative medicine. This study provided a simple protocol to isolate and culture BM-MSCs for clinical applications. Owing to supplementation with PRP, the 
BM-MSC culture medium became free of xenogeneic proteins, foreign viruses, and other infectious agents. Similar to BM-MSC cultured in FBS-supplemented medium, BM-MSCs cultured in PRP-supplemented medium maintained their phenotype, differentiation potential, as well as conserved their normal karyotype after 10 passages and did not form tumors in mice. This study also suggested that BM-MSCs could be cultured in a medium supplemented with $2.5 \%$ PRP. Considering these results, expanded BM-MSCs can satisfy the criteria underlying good manufacturing practice standards for clinical usage.

\section{Abbreviations}

aPRP: Activated platelet rich plasma; BM-MSC: Bone marrow mesenchymal stem cells; FBS: Fetal bovine serum; GVHD: Graft versus host disease; MNCs: Mononuclear cells: PBS: Phosphate buffer saline

\section{Competing interests}

The author declares that he has no competing interests.

\section{Acknowledgements}

This study was funded by Ministry of Science and Technology, Vietnam under grant Number DTDL.2012$\mathrm{G} / 23$.

\section{References}

Atashi, F., Jaconi, M.E., Pittet-Cuenod, B., and Modarressi, A. (2014). Autologous Platelet-Rich Plasma: A Biological Supplement to Enhance Adipose-Derived Mesenchymal Stem Cell Expansion. Tissue engineering Part C, Methods 10.1089/ten.TEC.2014.0206.
Brooke, G., Rossetti, T., Pelekanos, R., llic, N., Murray, P., Hancock, S., Antonenas, V., Huang, G., Gottlieb, D., Bradstock, K., et al. (2009). Manufacturing of human placenta-derived mesenchymal stem cells for clinical trials. British journal of haematology 144, 571-579.

Chambers, D.C., Enever, D., llic, N., Sparks, L., Whitelaw, K., Ayres, J., Yerkovich, S.T., Khalil, D., Atkinson, K.M., and Hopkins, P.M. (2014). A phase lb study of placenta-derived mesenchymal stromal cells in patients with idiopathic pulmonary fibrosis. Respirology (Carlton, Vic) 19, 1013-1018.

Chan-II, C., Young-Don, L., Heejaung, K., Kim, S.H., Suh-Kim, H., and Kim, S.S. (2013). Neural induction with neurogenin 1 enhances the therapeutic potential of mesenchymal stem cells in an amyotrophic lateral sclerosis mouse model. Cell transplantation 22, 855-870.

Choudhery, M.S., Badowski, M., Muise, A., and Harris, D.T. (2013). Comparison of human mesenchymal stem cells derived from adipose and cord tissue. Cytotherapy 15, 330-343.

Danielyan, L., Beer-Hammer, S., Stolzing, A., Sch Fer, R., Siegel, G., Fabian, C., Kahle, P., Biedermann, T., Lourhmati, A., Buadze, M., et al. (2014). Intranasal delivery of bone marrow derived mesenchymal stem cells, macrophages, and microglia to the brain in mouse models of Alzheimer?s and Parkinson?s disease. Cell transplantation 10.3727/096368914×684970.

Danielyan, L., Schafer, R., von Ameln-Mayerhofer, A., Bernhard, F., Verleysdonk, S., Buadze, M., Lourhmati, A., Klopfer, T., Schaumann, F., Schmid, B., et al. (2011). Therapeutic efficacy of intranasally delivered mesenchymal stem cells in a rat model of Parkinson disease. Rejuvenation research 14, 3-16.

de Carvalho Rodrigues, D., Asensi, K.D., Vairo, L., AzevedoPereira, R.L., Silva, R., Rondinelli, E., Goldenberg, R.C., Campos de Carvalho, A.C., and Urmenyi, T.P. (2012). Human menstrual blood-derived mesenchymal cells as a cell source of rapid and efficient nuclear reprogramming. Cell transplantation 21, 22152224.

Dominici, M., Le Blanc, K., Mueller, I., Slaper-Cortenbach, I., Marini, F., Krause, D., Deans, R., Keating, A., Prockop, D., and Horwitz, E. (2006). Minimal criteria for defining multipotent mesenchymal stromal cells. The International Society for Cellular Therapy position statement. Cytotherapy 8, 315-317.

Ezquer, F., Ezquer, M., Simon, V., Pardo, F., Yanez, A., Carpio, D., and Conget, P. (2009). Endovenous administration of bonemarrow-derived multipotent mesenchymal stromal cells prevents renal failure in diabetic mice. Biology of blood and marrow transplantation: journal of the American Society for Blood and Marrow Transplantation 15, 1354-1365.

Ferro, F., Spelat, R., and Baheney, C.S. (2014). Dental pulp stem cell (DPSC) isolation, characterization, and differentiation. Methods in molecular biology (Clifton, NJ) 1210, 91-115.

Friedenstein, A.J., Petrakova, K.V., Kurolesova, A.I., and Frolova, G.P. (1968). Heterotopic of bone marrow. Analysis of precursor cells for osteogenic and hematopoietic tissues. Transplantation 6, 230-247.

Huang, J., Sha, H., Wang, G., Bao, G., Lu, S., Luo, Q., and Tan, Q. (2014). Isolation and characterization of ex vivo expanded mesenchymal stem cells obtained from a surgical patient. Molecular medicine reports 10.3892/mmr.2014.2892.

Iudicone, P., Fioravanti, D., Bonanno, G., Miceli, M., Lavorino, C., Totta, P., Frati, L., Nuti, M., and Pierelli, L. (2014). Pathogenfree, plasma-poor platelet lysate and expansion of human mesenchymal stem cells. Journal of translational medicine 12 , 28.

Kebriaei, P., Isola, L., Bahceci, E., Holland, K., Rowley, S., McGuirk, J., Devetten, M., Jansen, J., Herzig, R., Schuster, M., et al. (2009). Adult human mesenchymal stem cells added to corticosteroid therapy for the treatment of acute graft-versushost disease. Biology of blood and marrow transplantation : journal of the American Society for Blood and Marrow 
Transplantation 15, 804-811.

Lee, H.K., Lim, S.H., Chung, I.S., Park, Y., Park, M.J., Kim, J.Y., Kim, Y.G., Hong, J.T., Kim, Y., and Han, S.B. (2014). Preclinical efficacy and mechanisms of mesenchymal stem cells in animal models of autoimmune diseases. Immune network 14, 81-88.

Lee, J.Y., Nam, H., Park, Y.J., Lee, S.J., Chung, C.P., Han, S.B., and Lee, G. (2011). The effects of platelet-rich plasma derived from human umbilical cord blood on the osteogenic differentiation of human dental stem cells. In vitro cellular \& developmental biology Animal 47, 157-164.

Leite, C., Silva, N.T., Mendes, S., Ribeiro, A., de Faria, J.P., Lourenco, T., Dos Santos, F., Andrade, P.Z., Cardoso, C.M. Vieira, M., et al. (2014). Differentiation of human umbilical cord matrix mesenchymal stem cells into neural-like progenitor cells and maturation into an oligodendroglial-like lineage. PloS one 9, el11059.

Li, T., Zhu, J., Ma, K., Liu, N., Feng, K., Li, X., Wang, S., and Bie, P. (2013). Autologous bone marrow-derived mesenchymal stem cell transplantation promotes liver regeneration after portal vein embolization in cirrhotic rats. The Journal of surgical research 184, 1161-1173.

Murphy, M.B., Blashki, D., Buchanan, R.M., Yazdi, I.K., Ferrari, M., Simmons, P.J., and Tasciotti, E. (2012). Adult and umbilical cord blood-derived platelet-rich plasma for mesenchymal stem cell proliferation, chemotaxis, and cryo-preservation. Biomaterials 33, 5308-5316.

Narbona-Carceles, J., Vaquero, J., B, S.S., Forriol, F., and Fernandez-Santos, M.E. (2014). Bone marrow mesenchymal stem cell aspirates from alternative sources is the knee as good as the iliac crest? Injury 45 Suppl 4, S42-47.

Odabas, S., Elcin, A.E., and Elcin, Y.M. (2014). Isolation and characterization of mesenchymal stem cells. Methods in molecular biology (Clifton, NJ) 1 109, 47-63.

Papadopoulou, A., Yiangou, M., Athanasiou, E., Zogas, N., Kaloyannidis, P., Batsis, I., Fassas, A., Anagnostopoulos, A., and Yannaki, E. (2012). Mesenchymal stem cells are conditionally therapeutic in preclinical models of rheumatoid arthritis. Annals of the rheumatic diseases 71, 1733-1740.

Pham, P.V., Vu, N.B., Pham, V.M., Truong, N.H., Pham, T.L., Dang, L.T., Nguyen, T.T., Bui, A.N., and Phan, N.K. (2014). Good manufacturing practice-compliant isolation and culture of human umbilical cord blood-derived mesenchymal stem cells. Journal of translational medicine 12,56.

Robey, P.G., Kuznetsov, S.A., Ren, J., Klein, H.G., Sabatino, M., and Stroncek, D.F. (2014). Generation of clinical grade human bone marrow stromal cells for use in bone regeneration. Bone 10.1016/j.bone.2014.07.020.

Vaes, B., Van't Hof, W., Deans, R., and Pinxteren, J. (2012). Application of MultiStem((R)) Allogeneic Cells for Immunomodulatory Therapy: Clinical Progress and Pre-Clinical Challenges in Prophylaxis for Graft Versus Host Disease. Frontiers in immunology 3, 345.

Vainshtein, J.M., Kabarriti, R., Mehta, K.J., Roy-Chowdhury, J., and Guha, C. (2014). Bone marrow-derived stromal cell therapy in cirrhosis: clinical evidence, cellular mechanisms, and implications for the treatment of hepatocellular carcinoma. International journal of radiation oncology, biology, physics 89 , 786-803.

Van Pham, P., Bui, K.H., Ngo, D.Q., Vu, N.B., Truong, N.H., Phan, N.L., Le, D.M., Duong, T.D., Nguyen, T.D., Le, V.T., et al. (2013). Activated platelet-rich plasma improves adipose-derived stem cell transplantation efficiency in injured articular cartilage. Stem cell research \& therapy 4, 91.

Van Pham, P., Vu, N.B., Phan, N.L.-C., Le, D.M., Truong, N.C., Truong, N.H., Bui, K.H.-T., and Phan, N.K. (2014). Good manufacturing practice-compliant isolation and culture of human adipose derived stem cells. Biomed Res Ther 1, 1-9.

Veronesi, F., Giavaresi, G., Tschon, M., Borsari, V., Nicoli Aldini, N., and Fini, M. (2013). Clinical use of bone marrow, bone marrow concentrate, and expanded bone marrow mesenchymal stem cells in cartilage disease. Stem cells and development 22, 181-192.

\section{Cite this article as:}

Pham, P., Phan, N., Le, D., Le, P., Tran, T., \& Phan, N. (2014). Good manufacturing practice-compliant isolation and culture of human bone marrow mesenchymal stem cells. Progress In Stem Cell, 1 (1):1827. doi:http://dx.doi.org/10.15419/psc.v1i1.48
Submit your next manuscript to Progress in STEM CELL and take full advantage of:

Convenient online submission

Thorough peer-review

No space constraints or color figure charges

Inclusion in Google Scholar

Research which is freely available for

redistribution

Online submission at:

http://www.springer.com/globalsciencejournals/progre ss+in+stem+cell?SGWID $=0-1770314-0-0-0$ 